\title{
Revisoría fiscal y sostenibilidad empresarial en Colombia ${ }^{1}$
}

\section{Fiscal review and corporate sustainability in Colombia}

DOI: http://dx.doi.org/10.17981/econcuc.38.2.2017.06

Recibido: ago 2/2017 Devuelto para revisión: sep 19/17 Aceptado: oct 9/2017

Wendell Archibold Barrios ${ }^{2}$

Loraines Aguilera Villafañe ${ }^{3}$

Adalberto Escobar Castillo ${ }^{4}$

\begin{abstract}
Resumen
El objetivo del artículo es establecer el impacto de las funciones del revisor fiscal en la sostenibilidad empresarial, tomando como referencia el punto de vista de diversos autores. Este trabajo se desarrolla desde un enfoque cualitativo, con alcance descriptivo y diseño documental. Se logra obtener evidencia clara que muestra que el revisor fiscal, mediante el cumplimiento de todas sus funciones, impacta en forma positiva el avance de la sostenibilidad empresarial a través del control que ejerce sobre las actuaciones de la administración. Se concluye que la revisoría fiscal influye en forma directa en el desarrollo de empresas con prácticas sostenibles.
\end{abstract}

Palabras claves: revisoría fiscal; sostenibilidad empresarial; responsabilidad social empresarial; interés general; fiscalización; control; empresas sostenibles

\begin{abstract}
The purpose of this article is to set the Statutory Auditor duties impact in the corporate sustaintability, taking as reference various authors' point of view. This research is developed from a qualitative approach, a descriptive scope and a documentary design. It was possible to find clear evidence showing that the statutory auditor, through the fulfillment of all its duties, positively impacts the progress of corporate sustainability through the control exercised over the administration's actions. It is concluded that the statutory auditor has a direct influence on the development of companies with sustainable practices.
\end{abstract}

Keywords: Statutory Audit; Business Sustainability; Corporate Social Responsibility; General Interest; Inspection; Control; Sustainable Companies.

${ }^{1}$ El presente artículo de reflexión es producto de la investigación: La revisoría fiscal y la sostenibilidad empresarial en las Pymes del sector exportador del departamento del Atlántico, en la línea de investigación "Contabilidad y Control” del grupo de investigación Organizaciones Sostenibles de la Universidad del Atlántico.

${ }^{2}$ Contador público. Especialista en Gestión Tributaria, Aduanera y Cambiaria. Magíster en Administración e Innovación. Estudiante del doctorado en Contabilidad de la Universidad Nacional del Rosario (Argentina). Profesor e investigador de la Universidad del Atlántico. Correo: wendellarchibold@mail.uniatlantico.edu.co

${ }^{3}$ Estudiante de Contaduría Pública de la Universidad del Atlántico. Integrante del semillero de investigación en Contabilidad y Control Organizacional, $\mathrm{C}_{2} \mathrm{O}$, de la facultad de Ciencias Económicas de la Universidad del Atlántico. Correo: loraines16031@ hotmail.es

${ }^{4}$ Contador público de la Universidad de la Costa, CUC. Magíster en Administración de la Universidad de la Costa, CUC. Profesor investigador, miembro del grupo de investigación GICADE de la misma institución. Joven investigador COLCIENCIAS convocatoria 673 de 2014. Correo: aescobar2@cuc.edu.co 


\section{Introducción}

En las últimas décadas se han gestado alrededor del mundo empresas con prácticas sostenibles desde las diferentes dimensiones que abarcan esta teoría (Teoría de empresas sostenibles); Colombia no ha sido la excepción debido a que el Estado ha regulado a través de alguna normatividad temas relacionados con el usufructo de los recursos naturales y el manejo del medio ambiente. Por otra parte, la existencia de una institución de control de origen legal podría coadyuvar a la gestación de empresas con prácticas sostenibles.

A lo largo del desarrollo de la revisoría fiscal, el representante de esta institución ha limitado sus funciones a dictaminar estados financieros, dejando de lado las demás funciones que le han sido conferidas por ley. Las funciones a las que se hace referencia son aquellas que están ligadas al control; a éste, le compete, desde su cargo, observar las actuaciones de la administración (la gestión), las cuales deben estar direccionadas hacia el desarrollo de una empresa sostenible desde las distintas dimensiones que esta implica (económica, social y ambiental).

En este sentido, el artículo tiene como propósito establecer el impacto de las funciones del revisor fiscal en la sostenibilidad empresarial. Actualmente, la sociedad espera que desde las empresas surja una conciencia ambiental que genere algún tipo de beneficio, con la finalidad que la empresa retribuya de alguna manera por el impacto que genera al medio ambiente en el desarrollo de su actividad económica.

El presente artículo de reflexión consta de la siguiente estructura: el análisis de las funciones del revisor fiscal desde diversas perspectivas de distintos exponentes del tema en el país; la evolución de la sostenibilidad en Colombia y, finalmente, los elementos que coinciden entre las dos variables en estudio con la finalidad de poner en evidencia el impacto del pleno cumplimiento de las funciones del revisor fiscal en el desarrollo de empresas con prácticas sostenibles.

La metodología aplicada en el artículo se fundamenta a partir de un enfoque cualitativo, de tipo descriptivo y con diseño no experimental documental. En la investigación se emplea la técnica de análisis textual, utilizado para datos cualitativos, a través de las cuales se realizarán las actividades de interpretación de los contenidos vinculados al objeto de estudio (categorías) con base en los textos seleccionados (Méndez, 2006; Vieytes, 2004; Arias, 2012; Hernández, Fernández y Baptista, 2014).

\section{Análisis de las funciones del revisor fiscal}

Revisoría fiscal. La revisoría fiscal se define como una institución de origen legal de carácter profesional que por ley está bajo la responsabilidad de un profesional de la ciencia contable, el cual está limitado al cumplimiento de sus funciones establecidas en la ley comercial del país (Consejo Técnico de la Contaduría Pública, 2008).

Se argumenta entonces, que la revisoría fiscal es más que una persona, es una institución de carácter legal en función de diversos actores e intereses y que actúa como garante entre la empresa y la sociedad (incluyendo al Estado); dicho esto, se afirma que esta institución se encarga de generar confianza a través de sus actuaciones a los diversos agentes de la sociedad en cuanto a la conservación de los recursos naturales, los valores sociales y el cumplimiento de los deberes legales de la misma (Consejo Técnico de la Contaduría Pública, 2008). 
Como cualquier institución, la revisoría fiscal está ligada a una serie de principios que rodean su ejercicio, los cuales se direccionan hacia una labor continua, constante e integra hacia las actuaciones de la administración y el manejo de los procedimientos establecidos para el desarrollo de la actividad económica; para esto, cuenta con plena objetividad e independencia que lo faculta para realizar una labor racional, que lo conlleve a tener una visión clara y veraz sobre el presente y posible futuro de la organización, esto apoyado en la facultad que le es conferida de dar fe pública.

A el revisor fiscal, en la investidura de su cargo, le son otorgados derechos que facilitan el cumplimiento de sus funciones: se le otorga la facultad de inspeccionar los libros de contabilidad, las operaciones administrativas, intervenir en las asambleas y usar recursos de la entidad en el cumplimiento de sus funciones (Ruiz, 2012). Así mismo, se establecen deberes adheridos a las funciones, tales como emitir en forma oportuna los informes, colaborar con entidades gubernamentales en caso de ser necesario y actuar según la normatividad vigente, además de abstenerse de divulgar hechos que conozca en el ejercicio de su labor; lo cual favorece la confianza en el ejercicio de la revisoría fiscal.

Finalmente, en este apartado se procede a hacer una revisión individual de cada una de las funciones que atañen al revisor fiscal como figura al interior de las organizaciones basados en las opiniones de diversos autores, entre los cuales se destacan trabajos de investigación revisados anteriormente, entre estos están: La orientación técnica profesional del Consejo Técnico de la Contaduría Pública (2008), el cual es una de las principales fuentes documentales al realizar investigaciones que contengan como variable la revisoría fiscal, o bien ésta sea el eje central de la misma; el autor Peña (2011), teniendo en cuenta que este es uno de los principales exponentes del tema en el país; Blanco (1988) atendiendo al aporte de una serie de conceptos e interpretaciones que hace a las funciones del revisor fiscal establecidas por el Decreto 2811 (Presidente de la Republica, 1974); además se recurre a la Circular Externa 115-000011 (Superintendencia de Sociedades, 2008), en la cual se hace mención a las funciones que se analizarán en el presente capítulo.

La revisoría fiscal y la sociedad. Teniendo en cuenta que el Estado Colombiano se muestra como interventor en las diversas dimensiones sociales, la revisoría fiscal ha sido, desde su aparición y a lo largo de su existencia, esa institución de control que, aunque está financiada en su totalidad por la misma empresa, actúa como ente fiscalizador de la misma.

La fuente de la cual se alimenta el ejercicio de la revisoría fiscal es la confianza pública, por lo cual se pone en evidencia la importancia de ésta en cuanto a lo que dictamina y a las opiniones que emite, las cuales deben garantizar que la empresa cumple a cabalidad con los estamentos legales que le conciernen en el desarrollo de sus actividades, por ende, se direcciona también hacia un tipo de control empresarial (Peña, 2011).

El revisor fiscal evalúa los sistemas de control de las organizaciones y emite dictamen e informa a quienes representa sobre los aspectos de interés público o privado con la finalidad de salvaguardar los intereses, no solo de los socios o accionistas, sino de la sociedad en general, incluido el Estado, dirigiendo esta actividad de control a la creación de empresas con prácticas sostenibles; así, a través del cumplimiento en pleno de sus funciones, el revisor fiscal contribuye en la gestión empresarial (Pinilla, 2008). 
REVISORÍA FISCAL Y SOSTENIBILIDAD EMPRESARIAL EN COLOMBIA

Wendell Archibold Barrios - Loraines Aguilera Villafañe - Adalberto Escobar Castillo

Tabla 1

Análisis de las Funciones del Revisor Fiscal

\begin{tabular}{|c|c|c|c|c|c|}
\hline & $\begin{array}{l}\text { Función "Código de } \\
\text { comercio" }\end{array}$ & $\begin{array}{c}\text { Consejo } \\
\text { técnico de la } \\
\text { Contaduría } \\
\text { Pública (2008) }\end{array}$ & $\begin{array}{c}\text { Super- } \\
\text { intendencia } \\
\text { de Sociedades } \\
(2008)\end{array}$ & $\begin{array}{c}\text { Jesús } \\
\text { María Peña } \\
\text { Bermúdez } \\
\text { (2011) }\end{array}$ & $\begin{array}{l}\text { Yanel Blanco } \\
\text { Luna (1988) }\end{array}$ \\
\hline 1. & $\begin{array}{l}\text { Cerciorarse de que } \\
\text { las operaciones que se } \\
\text { celebren o cumplan por } \\
\text { cuenta de la sociedad se } \\
\text { ajustan a las prescripcio- } \\
\text { nes de los estatutos, a las } \\
\text { decisiones de la asamblea } \\
\text { general y a las de la junta } \\
\text { directiva. }\end{array}$ & $\begin{array}{l}\text { Implica la } \\
\text { fiscalización de } \\
\text { funciones y tareas } \\
\text { relacionadas con } \\
\text { las operaciones } \\
\text { del ente } \\
\text { económico. }\end{array}$ & $\begin{array}{l}\text { Seguimiento } \\
\text { y análisis } \\
\text { para que la } \\
\text { administración } \\
\text { cumpla con } \\
\text { las normas } \\
\text { estatutarias. }\end{array}$ & $\begin{array}{l}\text { Realizar una } \\
\text { verdadera } \\
\text { interventoría } \\
\text { de cuentas. }\end{array}$ & $\begin{array}{l}\text { Examen crítico } \\
\text { de los hechos, } \\
\text { operaciones } \\
\text { o actos de la } \\
\text { administración. }\end{array}$ \\
\hline 2. & $\begin{array}{l}\text { Dar oportuna cuenta, por } \\
\text { escrito, a la asamblea o } \\
\text { junta de socios, a la junta } \\
\text { directiva o al gerente, se- } \\
\text { gún los casos, de las irre- } \\
\text { gularidades que ocurran } \\
\text { en el funcionamiento de la } \\
\text { sociedad y en el desarrollo } \\
\text { de sus negocios. }\end{array}$ & $\begin{array}{l}\text { Implica rendir } \\
\text { un informe a } \\
\text { los órganos } \\
\text { correspondientes. }\end{array}$ & $\begin{array}{l}\text { Oportuna } \\
\text { cuenta de las } \\
\text { irregularidades } \\
\text { que se presenten } \\
\text { en el ente } \\
\text { económico a } \\
\text { los órganos } \\
\text { correspondientes. }\end{array}$ & $\begin{array}{l}\text { Dar informe } \\
\text { por escrito } \\
\text { de cualquier } \\
\text { anomalía y } \\
\text { tener claro qué } \\
\text { medidas se } \\
\text { podrían tomar. }\end{array}$ & $\begin{array}{l}\text { El revisor } \\
\text { fiscal tendrá } \\
\text { sugerencias y } \\
\text { recomendaciones } \\
\text { para las } \\
\text { irregularidades } \\
\text { que se presenten. }\end{array}$ \\
\hline 3. & $\begin{array}{l}\text { Colaborar con las entida- } \\
\text { des gubernamentales que } \\
\text { ejerzan la inspección y vi- } \\
\text { gilancia de las compañías } \\
\text { y rendirles los informes a } \\
\text { que haya lugar o le sean } \\
\text { solicitados. }\end{array}$ & $\begin{array}{l}\text { Atestar con } \\
\text { destino a los } \\
\text { organismos } \\
\text { de control y } \\
\text { vigilancia toda } \\
\text { documentación } \\
\text { que requiera su } \\
\text { firma. }\end{array}$ & $\begin{array}{l}\text { Apoyo y ayuda } \\
\text { a las entidades } \\
\text { de vigilancia y } \\
\text { control cuando } \\
\text { éstas así lo } \\
\text { requieran. }\end{array}$ & $\begin{array}{l}\text { Coadyuvar con } \\
\text { los organismos } \\
\text { de inspección, } \\
\text { control y } \\
\text { vigilancia, } \\
\text { hasta el } \\
\text { límite de sus } \\
\text { funciones. }\end{array}$ & $\begin{array}{l}\text { Colaborar con } \\
\text { las entidades } \\
\text { de control que } \\
\text { haya impuesto el } \\
\text { Estado para la } \\
\text { vigilancia de la } \\
\text { sociedad. }\end{array}$ \\
\hline 4. & $\begin{array}{l}\text { Velar por que se lleven } \\
\text { regularmente la contabi- } \\
\text { lidad de la sociedad y las } \\
\text { actas de las reuniones de } \\
\text { la asamblea, de la junta } \\
\text { de socios y de la junta } \\
\text { directiva, y porque se } \\
\text { conserven debidamente la } \\
\text { correspondencia de la so- } \\
\text { ciedad y los comprobantes } \\
\text { de las cuentas, impartien- } \\
\text { do las instrucciones nece- } \\
\text { sarias para tales fines. }\end{array}$ & $\begin{array}{l}\text { El revisor fiscal } \\
\text { debe cerciorarse } \\
\text { de que todo acto } \\
\text { o decisión de la } \\
\text { administración } \\
\text { se ajuste a } \\
\text { la normativa } \\
\text { vigente. }\end{array}$ & $\begin{array}{l}\text { Verificación } \\
\text { de criterios y } \\
\text { procedimientos } \\
\text { para que la } \\
\text { sociedad lleve la } \\
\text { contabilidad. }\end{array}$ & $\begin{array}{l}\text { Impartir } \\
\text { instrucciones } \\
\text { necesarias } \\
\text { apoyadas en } \\
\text { la ley para el } \\
\text { manejo de la } \\
\text { contabilidad en } \\
\text { la entidad. }\end{array}$ & $\begin{array}{l}\text { Basa la } \\
\text { importancia de } \\
\text { la contabilidad } \\
\text { como elemento } \\
\text { probatorio en } \\
\text { la legislación } \\
\text { colombiana. }\end{array}$ \\
\hline 5. & $\begin{array}{l}\text { Inspeccionar asiduamente } \\
\text { los bienes de la sociedad } \\
\text { y procurar que se to- } \\
\text { men oportunamente las } \\
\text { medidas de conservación } \\
\text { o seguridad de los mismos } \\
\text { y de los que ella tenga en } \\
\text { custodia a cualquier otro } \\
\text { título. }\end{array}$ & $\begin{array}{l}\text { Examinar } \\
\text { frecuente y } \\
\text { cuidadosamente } \\
\text { todos los bienes } \\
\text { que posea la } \\
\text { entidad. }\end{array}$ & $\begin{array}{l}\text { Plena certeza } \\
\text { de que el ente } \\
\text { cumple con } \\
\text { las medidas } \\
\text { de control } \\
\text { apropiadas para } \\
\text { salvaguardar el } \\
\text { patrimonio. }\end{array}$ & $\begin{array}{l}\text { Desprende una } \\
\text { auditoria del } \\
\text { control interno } \\
\text { en defensa del } \\
\text { patrimonio de } \\
\text { la sociedad. }\end{array}$ & $\begin{array}{l}\text { Medidas de } \\
\text { seguridad de } \\
\text { los bienes como } \\
\text { pólizas de seguro } \\
\text { y garantía } \\
\text { material de los } \\
\text { mismos. }\end{array}$ \\
\hline
\end{tabular}




\begin{tabular}{|c|c|c|c|c|}
\hline $\begin{array}{l}\text { 6. Impartir las instrucciones, } \\
\text { practicar las inspecciones } \\
\text { y solicitar los informes que } \\
\text { sean necesarios para esta- } \\
\text { blecer un control permanen- } \\
\text { te sobre los valores sociales. }\end{array}$ & $\begin{array}{l}\text { Impartir } \\
\text { instrucciones } \\
\text { para la debida } \\
\text { seguridad de } \\
\text { los valores } \\
\text { sociales, activos } \\
\text { intangibles. }\end{array}$ & $\begin{array}{l}\text { Manifestar } \\
\text { cuando considere } \\
\text { que no existen } \\
\text { los controles } \\
\text { necesarios para } \\
\text { los bienes y } \\
\text { valores sociales } \\
\text { de la sociedad. }\end{array}$ & $\begin{array}{l}\text { Inspecciones } \\
\text { que considere } \\
\text { necesarias } \\
\text { para tener } \\
\text { seguridad } \\
\text { sobre los bienes } \\
\text { sociales. }\end{array}$ & $\begin{array}{l}\text { Velar porque } \\
\text { el sistema de } \\
\text { contabilidad sea } \\
\text { adecuado para la } \\
\text { entidad. }\end{array}$ \\
\hline $\begin{array}{l}\text { 7. Autorizar con su firma cual- } \\
\text { quier balance que se haga, } \\
\text { con su dictamen o informe } \\
\text { correspondiente. }\end{array}$ & $\begin{array}{l}\text { Autorizar con su } \\
\text { firma los estados } \\
\text { financieros y las } \\
\text { declaraciones } \\
\text { tributarias a } \\
\text { que haya lugar y } \\
\text { emitir informe. }\end{array}$ & $\begin{array}{l}\text { Exposición } \\
\text { de un juicio } \\
\text { profesional sobre } \\
\text { la razonabilidad } \\
\text { de los estados } \\
\text { financieros. }\end{array}$ & $\begin{array}{l}\text { Autorizar } \\
\text { con su firma } \\
\text { todo estado } \\
\text { financiero y } \\
\text { emitir informe. }\end{array}$ & $\begin{array}{l}\text { Los estados } \\
\text { financieros deben } \\
\text { estar firmados } \\
\text { por el revisor } \\
\text { fiscal y tener } \\
\text { adjunto el debido } \\
\text { informe. }\end{array}$ \\
\hline $\begin{array}{l}\text { 8. Convocar a la asamblea o a } \\
\text { la junta de socios a reunio- } \\
\text { nes extraordinarias cuando } \\
\text { lo juzgue necesario. }\end{array}$ & $\begin{array}{l}\text { El revisor fiscal } \\
\text { podrá convocar a } \\
\text { Asamblea o junta } \\
\text { de socios basado } \\
\text { en su juicio } \\
\text { profesional. }\end{array}$ & $\begin{array}{l}\text { No se agregan } \\
\text { comentarios o } \\
\text { interpretaciones } \\
\text { adicionales } \\
\text { por parte de la } \\
\text { entidad. }\end{array}$ & $\begin{array}{l}\text { Independencia } \\
\text { para convocar } \\
\text { asambleas que } \\
\text { se realizaran } \\
\text { de forma } \\
\text { extraordinaria. }\end{array}$ & $\begin{array}{l}\text { Dan lugar } \\
\text { a reuniones } \\
\text { extraordinarias } \\
\text { por } \\
\text { irregularidades o } \\
\text { necesidades de la } \\
\text { entidad. }\end{array}$ \\
\hline $\begin{array}{l}\text { 9. Cumplir las demás atribu- } \\
\text { ciones que le señalen las le- } \\
\text { yes o los estatutos y las que, } \\
\text { siendo compatibles con las } \\
\text { anteriores, le encomiende la } \\
\text { asamblea o junta de socios. }\end{array}$ & $\begin{array}{l}\text { Deja abierta } \\
\text { para que le sean } \\
\text { otorgadas al } \\
\text { revisor fiscal } \\
\text { otras funciones o } \\
\text { atribuciones. }\end{array}$ & $\begin{array}{l}\text { Demás } \\
\text { atribuciones que } \\
\text { le sean otorgadas } \\
\text { al revisor fiscal. }\end{array}$ & $\begin{array}{l}\text { Dispone la } \\
\text { posibilidad del } \\
\text { nacimiento } \\
\text { de nuevas } \\
\text { funciones. }\end{array}$ & $\begin{array}{l}\text { Cumplir con los } \\
\text { estatutos que } \\
\text { le adicione la } \\
\text { asamblea o junta } \\
\text { de socios además } \\
\text { también las } \\
\text { funciones que le } \\
\text { adicione la ley. }\end{array}$ \\
\hline
\end{tabular}

Fuente: Elaboración propia

Control de la gestión de revisoría fiscal. Se hace necesario que el revisor fiscal posea un amplio conocimiento acerca de las funciones que le son taxativamente delegadas por ley con el objetivo de que cumpla a cabalidad con éstas, coadyuvando no solo al crecimiento de la organización en la cual desempeña su cargo, sino también a generar confianza en los usuarios de la información de la revisoría fiscal; en muchas ocasiones, la revisoría fiscal es vista como la práctica de una auditoría externa. Con respecto a esto, Blanco (1988) afirma que:
La influencia que viene ejerciendo la auditoría externa sobre la revisoría fiscal y, por qué no decirlo, la mala imagen que nos hemos encargado de darle los contadores públicos a esta última, han hecho que los contadores no tengamos conocimiento cabal de la revisoría fiscal y que no nos hayamos preocupado por estudiar: si hay o no diferencia con la auditoría externa y, de haberlas, cuáles serían las diferencias fundamentales; el grado de responsabilidad del revisor fiscal con el control interno de la sociedad $\mathrm{y}$ muchos otros asuntos que requieren precisión de la revisoría fiscal ( $p$. 440). 
Las funciones del revisor fiscal al interior de las organizaciones se vinculan directamente con la gestión empresarial, al respecto, Curvelo y Clavijo (s.f.) afirman que se requiere un control de la gestión que posibilite el desarrollo en cuanto al cumplimiento de planes, programas y demás establecidos al interior de la misma; este tipo de control se promueve desde el ejercicio de la revisoría fiscal, apoyada en su función de fiscalización.

\section{Sostenibilidad en Colombia}

\section{La Responsabilidad Social Empresarial} como antesala de la Sostenibilidad Empresarial. Según Gómez (2005), la Responsabilidad Social Empresarial (RSE) consiste en la asunción voluntaria, por parte de las empresas, de responsabilidades derivadas de los efectos de su actividad sobre el mercado y la sociedad, así como sobre el medio ambiente y las condiciones de desarrollo humano.

Los antecedentes de la responsabilidad social (RS) no tienen indicios claros de su gestación, sin embargo, se deduce que en el siglo XIX se documentan los primeros aportes sobre este tema, donde, por primera vez, se gestan las prácticas de las empresas en pro de sus trabajadores (Pérez, Epinoza y Peralda, 2016).

La sostenibilidad empresarial como apuesta al futuro. Smith (1776) sustenta a partir de su teoría económica que la participación del Estado debe ser limitada debido a que el mercado se rige por una fuerza invisible (ley de oferta y demanda). Este escenario obliga a las empresas a convertirse en organizaciones sostenibles a nivel económico, social y ambiental, con el fin último de permanecer competitivas en el mercado.

Actualmente, la globalización ha desbordado la capacidad real de los Estados para regular con sus políticas públicas el mínimo de dignidad frente a los derechos humanos, civiles, políticos; así como los económicos, sociales y ecológicos. Esta incapacidad ha conllevado a que las empresas desarrollen una forma de garantizar estos derechos para toda la sociedad en general, lo cual aporta a la misma un posicionamiento, no solo económico sino también en materia social y ambiental, que garantiza en cierta forma el mantenimiento de la entidad productiva en el mercado con el paso del tiempo (Navarro, 2013).

El desarrollo sostenible y la sustentabilidad se han entendido no como un producto hacia el cual haya que aspirar, sino como procesos de cambio que pueden ser conducidos por ciertos principios (UNESCO y Griffith University, 2002). De esta manera, las organizaciones van encaminadas hacia un modelo empresarial basado en la sostenibilidad, éste, a su vez, se rige por principios económicos, sociales y ambientales que benefician en gran medida a la sociedad en general.

Es necesario mencionar que uno de los elementos que promueven el éxito de la gestión sostenible de stakeholders corresponde a la creación de valor en los ámbitos económico, social y ambiental, de esta manera, la empresa tendrá un crecimiento que mire hacia las diferentes direcciones, es decir, el beneficio no será solo para los accionistas o socios de la organización sino para los empleados, proveedores, clientes y demás involucrados (Díaz y Castaño, 2015).

Cifras de la evolución de la sostenibilidad en Colombia. En Colombia se ha generado toda una estructura de Derecho ambiental que comenzó con la expedición del Decreto 2811(Presidente de la República de Colombia, 1974) y la Ley 9 (Presidente de la Republica de Colombia, 1979); sin embargo, es a partir de la Constitución Política de Colombia (Asamblea Nacional Constituyente, 1991) y de la expedición de la Ley 99 (Presidente de la República de Colombia, 1993) cuando la dimensión ambiental se consolida dentro del marco jurídico colombiano (Rodríguez, 2011, pág. 39). 
Por esta razón, cabe destacar que, en el país, el término de desarrollo sostenible tiene sus orígenes a partir de la promulgación de la Carta Magna de 1991; en ésta se ponen en evidencia grandes avances en el país con temas relacionados al medio ambiente y la protección de los recursos naturales. El tema de sostenibilidad es uno de los pilares de la Constitución Política de Colombia (Asamblea Nacional Constituyente, 1991); por lo cual toman fuerzas conceptos como desarrollo sostenible, patrimonio ecológico y calidad de vida.

En las últimas décadas se ha propagado en el contexto internacional los conocidos informes GRI (por sus siglas en ingles de Global Reporting Iniciative); traducido al castellano se usa la expresión Memoria de sostenibilidad para referirse a los informes que arrojan datos cuantitativos y cualitati- vos que reflejan el comportamiento social, económico y medio-ambiental de las empresas en su entorno. El objetivo de estos, anteriormente conocidos como informes de RSE (Responsabilidad Social Empresarial), es mostrar el desempeño de la organización en una triple línea de resultados.

En Colombia, la producción de estos informes ha tenido un avance desde el año 2006 debido a que a partir de ese momento y hasta el 2010 se ubicó en el quinto lugar de la región. Cabe resaltar que, en el país, el sector donde se produjo la mayoría de estos fue en el de la energía; este avance se puede observar a través de la gráfica 1 . Según datos del Consejo Empresarial Colombiano para el Desarrollo Sostenible (CECODE) (2016), Colombia se encuentra entre los países con mayor cantidad de reportes de sostenibilidad.

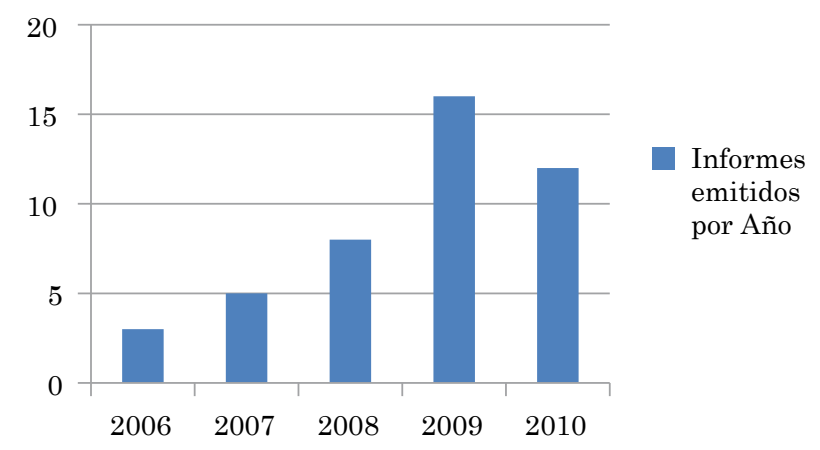

Gráfica 1. Número de informes de sostenibilidad emitidos en Colombia entre los años 2006 y 2010. Fuente: Elaboración propia a partir de Gómez (2012).

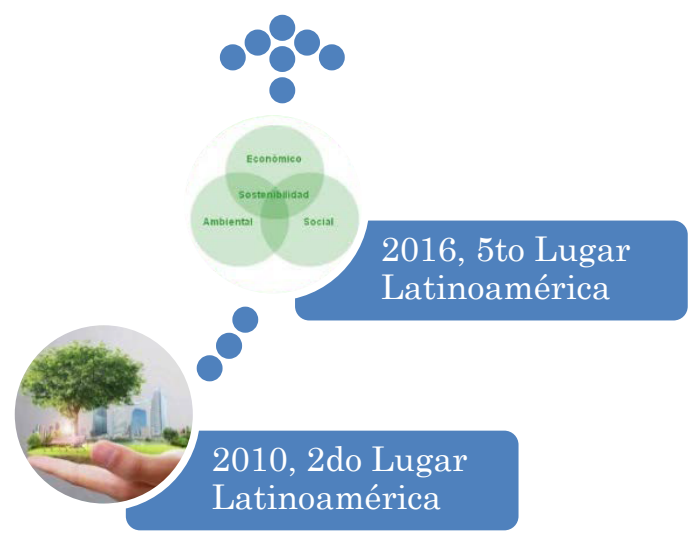

Gráfica 2. Avance de Colombia en materia de sostenibilidad en la región. Fuente: Elaboración propia con base en datos del CECODE (2016). 


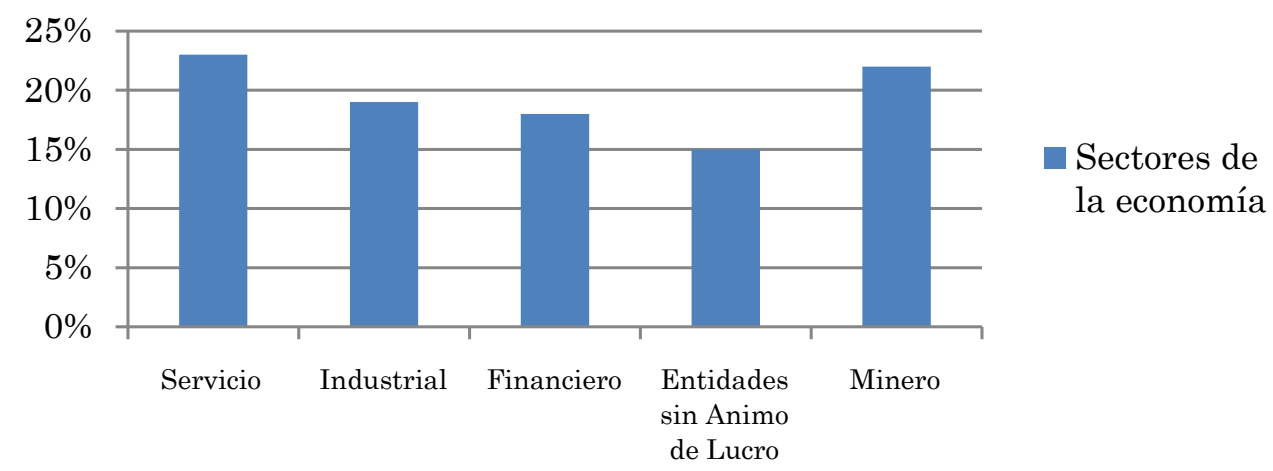

Gráfica 3. Reportes por sectores de informes de sostenibilidad Colombia. Fuente: Elaboración propia con base a datos de CECODE, (2016).

Resulta pertinente hacer mención de aquellos sectores de la economía donde se producen la mayor cantidad de informes GRI, teniendo en cuenta que no son todos los sectores de la economía colombiana los que han optado por adoptar practicas sostenibles, no producen ningún tipo de informe de sostenibilidad. En la siguiente gráfica se muestra la relación de esos sectores de la economía que actualmente emiten la mayor cantidad de informes de sostenibilidad (Gómez, 2012).

\section{Elementos que coinciden entre el cumplimiento de las funciones del revisor fiscal y las prácticas sostenibles de las empresas}

Una vez analizadas las funciones del revisor fiscal establecidas por ley en el país y revisado las cifras de la sostenibilidad empresarial en Colombia desde un punto de vista regional e internacional, se procede a establecer las incidencias de la revisoría fiscal en el desarrollo sostenible de las entidades.

La revisoría fiscal se hace responsable del buen funcionamiento de la empresa, del buen manejo de la administración y de la correcta gestión por parte de ésta en el medio en el cual desarrolla su actividad económica. Esta afirmación parte desde la premisa que las funciones del revisor fis- cal se enfocan hacia dos perspectivas un tanto distantes la una de la otra: la primera parte desde la obligación del revisor fiscal de dictaminar sobre estados financieros, mientras la segunda, pero no menos importante, se direcciona hacia la fiscalización de la gestión.

Se le atribuye a este segundo enfoque la segunda función establecida a partir del Decreto 410 (Presidente de la Republica de Colombia, 1971), el cual determina que los revisores fiscales deben dar oportuna cuenta, por escrito, a la asamblea o junta de socios, a la junta directiva o al gerente, según los casos, de las irregularidades que ocurran en el funcionamiento de la sociedad y en el desarrollo de sus negocios.

Teniendo en cuenta que la revisoría fiscal surge como ente de control del Estado hacia la empresa, se gesta el argumento que la revisoría fiscal obedece a un interés general en cabeza del Estado con la finalidad de salvaguardar los intereses de las sociedad en general; y que la sostenibilidad se basa primordialmente en que la actividad económica que realizan las empresas no vayan en detrimento del bien común, sino que la misma, en el pleno desarrollo de sus operaciones, genere beneficios a todos (socios, empleados, proveedores, Estado y comunidad en general). 
El éxito de una entidad se fundamenta en gran medida en el buen desarrollo de sus procedimientos internos; para hacer cumplir esta aseveración, la administración se direcciona hacia lo que se conoce como sistema de control interno. Éste es definido coloquialmente como el conjunto de normas, políticas, planes y procedimientos establecidos por la entidad para llevar a cabo los procesos internos de la misma en ciclo normal de las operaciones.
La revisoría fiscal interviene directamente en el control interno cuando la ley le otorga la función de impartir las instrucciones, practicar las inspecciones y solicitar los informes que sean necesarios para establecer un control permanente sobre los valores sociales, de esta manera, podrá intervenir en la forma que tiene la empresa para proteger sus valores sociales, que finalmente están ligados a la creación de una empresa sostenible. A continuación, se muestra en la gráfica 4 las coincidencias encontradas.

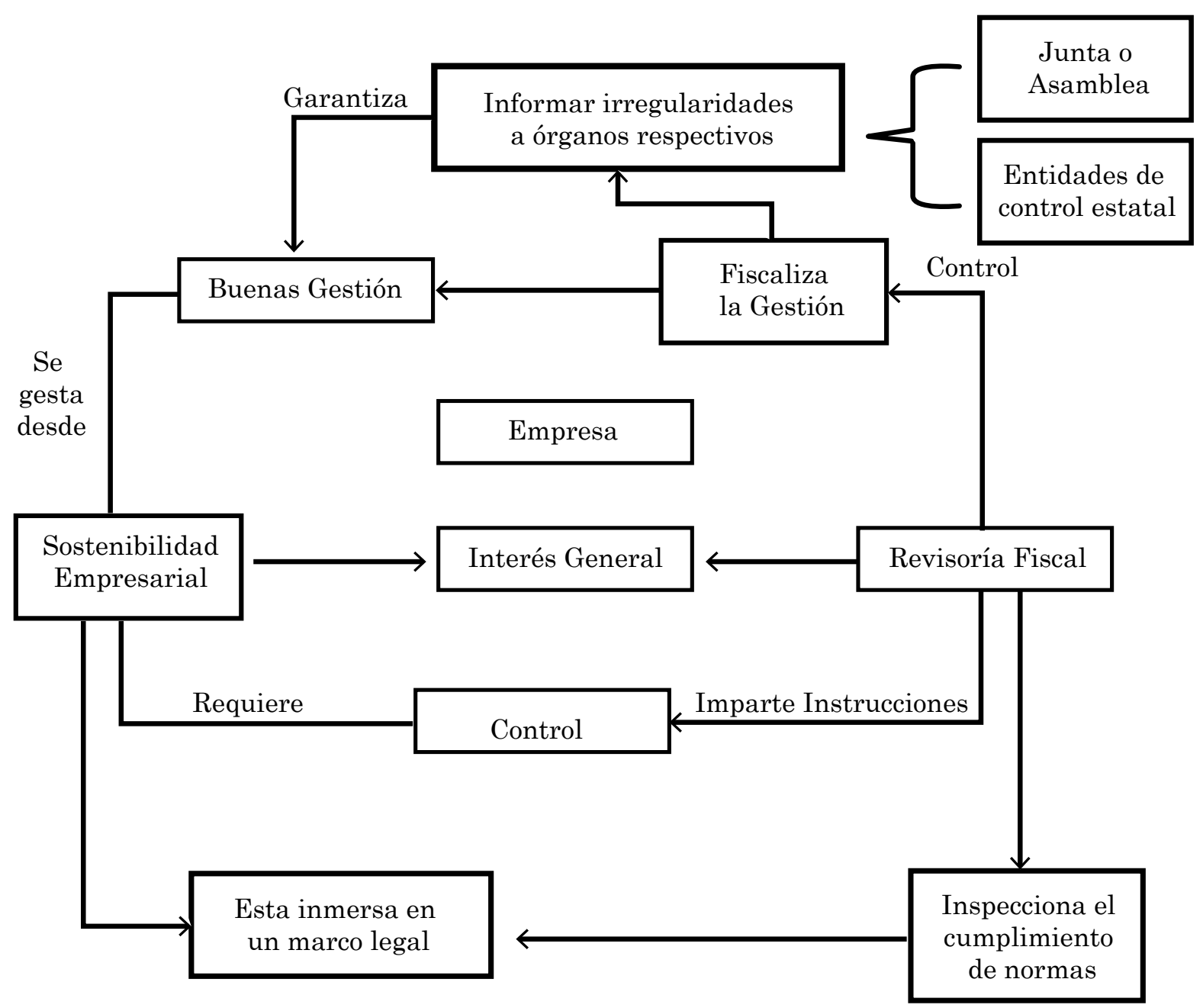

Gráfica 4. Elementos que coinciden entre la revisoría fiscal y la sostenibilidad empresarial. Fuente: Elaboración propia. 


\section{Conclusiones}

La revisoría fiscal, desde su aparición, tiene adheridas una serie de funciones que le confieren algunas facultades al interior de las entidades, éstas, ya analizadas desde los diversos autores citados en la investigación realizada, le otorgan a su representante la facilidad de poder influir en el pleno y correcto desarrollo de la empresa coadyuvando al fomento de una empresa sostenible.

Una vez realizada esta investigación se podría afirmar que el ejercicio de la revisoría fiscal logra contribuir, en gran medida, a la sostenibilidad empresarial, desde el punto de vista que ésta tiene una serie de funciones enfocadas hacia el control de las organizaciones, como la fiscalización de las actuaciones de la administración, que, de ser correctas, llevarían a las empresas al equilibrio constante entre el crecimiento económico y mantenimiento de un ambiente sano que garantice la supervivencia de las futuras generaciones (sostenibilidad empresarial).

A partir de este trabajo de investigación se podrían desprender otras investigaciones en esta misma línea, por ejemplo, se podría gestar un trabajo de investigación que buscara relacionar la revisoría fiscal con el manejo de los valores sociales de las empresas, enfocados no solo a activos intangibles sino también a la creación de un valor agregado de la empresa a partir de recursos como el capital intelectual.

Finalmente, con base en el análisis de la literatura seleccionada para el desarrollo de la presente investigación y teniendo en cuenta las dos variables analizadas, además de las coincidencias encontradas entre éstas, se procede a recomendar que la revisoría fiscal debe no solo conocer sino también cumplir a cabalidad con las funciones que le son otorgadas si la finalidad de ésta es el crecimiento integral de la empresa, aportando así de manera positiva en su desarrollo integral; además, el revisor fiscal debe tener claro que su papel en el desarrollo de la sostenibilidad es de vital importancia.

\section{Referencias}

Arias, F. (2012). El proyecto de investigación. Introducción a la metodología científica ( $6^{a}$ ed.). Caracas: Episteme.

Asamblea Nacional Constituyente. (1991). Constitución Política de Colombia. Bogotá, D.C.

Blanco, Y. (1988). Manual de auditoría y revisoría fiscal. Cali: Roesga.

Consejo Empresarial Colombiano para el Desarrollo Sostenible (CECODE) (2016). Colombia es segundo en sostenibilidad empresarial en Latinoamérica. Dinero. Recuperado de: http://www. dinero.com/empresas/articulo/colombia-es-segundo-en-sostenibilidad-empresarial-en-latinoamerica/237453.

Consejo Técnico de la Contaduría Pública. (2008). Documento de orientación profesional: Ejercicio profesional de la revisoria fiscal. Bogotá, D.C.: Consejo Técnico de la Contaduría Pública.

Curvelo, J. y Clavijo, F. (s.f.). Responsabilidad social del Revisor Fiscal en los procesos de sustenatabilidad de las organizaciones. Recuperado de: http:// www.javeriana.edu.co/personales/ hbermude/nov/memorias_rev_fiscal_ foro_firmas/eventos_rev_fiscal/III_revisoria_fiscal/ponencia_jose_curvelo_ fernando_clavijo_u_cooperativa.pdf. 
Díaz, N., y Castaño, C. (2015). Stakeholders: Base de la Sostenibilidad Empresarial. International Journal of Good Conscience, 10(2), 94-108.

Gómez, F. (2005). Responsabilidad social de las empresas: Fundamentos y enfoques de la gestión responsable. Cuadernos Forética 9. Madrid: Forética

Gómez, M. (2012). Los informes de responsabilidad social empresarial: $\mathrm{Su}$ evolución y tendencias en el contexto internacional colombiano. Cuadernos de contabilidad, 13(32), 121158.

Hernández, R., Fernández, C., y Baptista, M. (2014). Metodología de la investigación ( $6^{\mathrm{a}}$ ed.). México, D.F.: Mc Graw Hill.

Méndez, C. (2006). Metodología: Diseño desarrollo del proceso de investigación con enfasis en ciencias empresariales. ( $4^{\mathrm{a}}$ ed.). Bogotá, D.C.: Limusa.

Navarro, F. (2013). Responsabilidad Social Corporaiva: Teoría y práctica. México D.F.: Alfaomega.

Peña, J (2011). Revisoría fiscal: Una garantía para la empresa, la sociedad y el Estado. Bogotá, D.C.: Ecoe.

Pérez, M., Espinoza, C., y Peralda, B. (2016). La responsabilidad social empresarial y su enfonque ambiental: Una visión sostenible al futuro. Revista Universidad y Sociedad, 8(3), 169-178.

Pinilla, F. (2008). Revisoría fiscal: Sistema de fiscalización integral, permanente, preventivo e independiente. II encuentro de docentes de Revisoría fiscal (6-7). Bogotá, D.C.: Universidad Externado de Colombia.
República de Colombia. Presidencia de la Republica. (27 de marzo de 1971). Por el cual se expide el Código de Comercio. [Decreto 410 de 1971]. Bogotá, D.C.: DO: 33.339

República de Colombia. Presidencia de la República. (18 de diciembre de 1974). Por el cual se dicta el Código Nacional de Recursos Naturales Renovables y de Protección al Medio Ambiente. [Decreto 2811 de 1974]. Bogotá, D.C.: DO: 34243.

República de Colombia. Presidencia de la República. (24 de enero de 1979). Por la cual se dictan Medidas Sanitarias. [Ley 9 de 1974]. Bogotá, D.C.: DO: 35308 .

República de Colombia. Presidencia de la República. (22 de diciembre de 1993). Por la cual se crea el Ministerio del Medio Ambiente, se reordena el Sector Público encargado de la gestión y conservación del medio ambiente $y$ los recursos naturales renovables, se organiza el Sistema Nacional Ambiental, SINA, y se dictan otras disposiciones. [Ley 99 de 1993]. Bogotá, D.C.: DO: 41.146 .

Rodríguez, D. (2011). Contabilidad ambiental: Fundamentos epistemológicos, humanistas y legales. Revista Económicas CUC, 32(1). 35-44.

Ruiz, R. (2012). Fiscalización estratégica de arquitectura organizacional: Una tecnología para la Revisoría Fiscal. Bogotá, D.C.: Universidad Libre.

Superintendencia de Sociedades. (2008). Circular Externa 115-00001: Referente a la revisoría fiscal. Bogotá, D.C.: Superintendencia de Sociedades.

Smith, A. (1776). La riqueza de las naciones. Valladolid: William Strahan. 
REVISORÍA FISCAL Y SOSTENIBILIDAD EMPRESARIAL EN COLOMBIA

Wendell Archibold Barrios - Loraines Aguilera Villafañe - Adalberto Escobar Castillo

UNESCO y Griffith University. (2002).

Teaching and learning for a sustainable future. Recuperado de: www. unesco.org/education/tlsf/intro/ uncofrm_o.htm.
Vieytes, R. (2004). Metodología de la investigación en organizaciones, mercado y sociedad: epistemología y técnicas. Buenos Aires: Editorial de las Ciencias. 